\title{
Pengaruh Variasi Produk Dan Fasilitas Terhadap Minat Beli Ulang Konsumen Pada Ilo Peta Kota Bima
}

\author{
Marheiningsih ${ }^{1)}$, Amirulmukminin ${ }^{2)}$ \\ ${ }^{1,2}$ Prodi Manajemen, STIE BIMA \\ Email:' marheiningsih2016.stiebima@gmail.com \\ 2email: amirul.stiebima@gmail.com
}

\begin{abstract}
Abstrak. Penelitian asosiatif ini dilakukan untuk melihat ada tidaknya pengaruh variasi produk dan Falitas terhadap minat beli ulang konsumen pada Café Ilo Peta Kota Bima. Instrumen disusun menggunakan skala liker yang dibagikan 96 sampel dari dari populasi tidak diketahui. Kuisioner diuji validitas dan reliabiltas, dan hasilnya semua pernyataan yang disusun valid dan reliabel, sehingga kuisioner layak dibagikan untuk alat pengambilan data. Dari hasil analisis data menggunakan aplikasi SPSS versi 20, secara parsial Variasi Produk memberi pengaruh terhadap Minat Beli Ulang Konsulmen Pada Café Ilo Peta Kota Bima, hal itu ditandai dengan nilai nilai Sig $=0.000<\alpha=0.05$. Hal yang sama juga terjadi pada fasilitas, bahwa Fasilita ikut mempengaruhi minat beli ulang konsumen pada Café Ilo Peta Kota Bima karnea dilihat dari nilai Sig $=0.04<\alpha=$ 0.05. Dilihat dari hubungan secara Simultan, Variasi Produk dan Fasilitas secara bersama-sama mempengaruhi minat beli ulang pada Café Ilo Peta Kota Bima karena nilai Sig yaitu lebih kecil dari $\alpha$ atau standar error $(0,000<0,05)$.
\end{abstract}

Abstract. This associative research was conducted to see whether there was an effect of variations in products and facilities on consumer repurchase interest at the Café Ilo Peta Kota Bima. The instruments were arranged using a liker scale which distributed 96 samples from an unknown population. The questionnaire was tested for validity and reliability, and the results were all statements made were valid and reliable, so the questionnaire was worthy of being distributed for data collection tools. From the results of data analysis using the SPSS version 20 application, partially Product Variations have an effect on the Consumer Buyback Interest in Cafe Ilo Map of the City of Bima, it is marked by the value of Sig $=0,000<\alpha=0.05$. The same thing also happened at the facility, that the Facilitator also influenced the consumer's repurchase interest in the Cafe Ilo Map of the City of Bima because of the value of Sig $=0.04<\alpha=0.05$. Seen from the Simultaneous relationship, Product and Facility Variations together affect the repurchase interest in Bima Café Ilo Map because the Sig value is smaller than $\alpha$ or standard error $(0,000<0.05)$.

Kata Kunci : Variasi Produk, Fasilitas, Minat Beli Ulang 


\section{PENDAHULUAN}

Café-cafe tengah berkembang dengan pesat di Kota Bima. Sebut saja beberapa diantaranya Ilo Peta, Food Box, Yuank Cafe dan banyak lainnya. Hal itu, menyebabkan tingkat persaingan semakin tinggi dalam menarik minat konsumen. Peran inovasi dilakukan oleh pengelola café, seperti Variasi produk dan fasilitas yang disediakan. Varisi produk bukan sesuatu yang baru dalam dunia pemasara. Stategi ini jauh jauh hari telah digunakan terutama dalam peluncuran produk atau promosi produk. Faradisa, Budi dan Minarsih (2016) menjelaskan variasi produk merukapan strategi perusahaan dengan menganekaragamkan produknya dengan tujuan konsumen mendapatkan produk yang diinginkan dan dibutuhkan. Hal lain yang menjadi stategi pemasaran dengan menyediakann fasilitas yang menarik dan lengkap. Fasilitas ini merupakan penyediaan perlengkapan fisik untuk memenuhi kebutuhan konsumen.

Pada Perjalanannya, Café Ilo Peta saat pertama kali launching sangat ramai dikunjungi. Fasilitas yang mengambarkan ke khasan masyarakat Bima yang tradisional ditambha dengan beragam menu yang disajikan. Namun belakangan ini, pengunjung semakin berkurang. Tentu saja masalah ini harus terpecahkan, sehingga perlu diketahui bahaimana pengaruh Variasi Produk dan Fasilitas terhadap Minat Beli ulang Konsumen di Café Ilo Peta, baik secara parsial maupun secara simultan.

\section{KAJIAN LITERATUR}

\section{a. Variasi produk}

variasi produk atau keberagaman produk bukan hal baru dalam dunia pemasaran, dimana strategi ini banyak digunakan oleh praktisi-praktisi pemasaran didalam aktivitas peluncuran produk. Menurut philip kotler (2009:72), Variasi produk sebagai ahli tersendiri dalam suatu merek atau ini produk yang dapat dibedakan berdasarkan ukuran, harga, penampilan atau ciri-ciri. Jika cafe menyediakan menu yang beraneka ragam, akan lebih memudahkan cafe untuk menarik konsumen agar bersantap ditempatnya. Karena semakin banyak pilihan yang disediakan cafe, maka akan semakin memudahkan konsumen untuk memilih menu sesuai keinginanya. Indikator variasi produk yang digunakan dalam penelitian ini adalah Ukuran, harga, dan tampilan.

\section{b. Fasilitas}

fasilitas merupakan saranan yang menyediakan perlengkapan fisik guna menunjang kebutuhan konsumen agar konsumen merasa lebih nyaman dan kebutuhan konsumen terpenuhi. Menurut sulastyono (1999), Fasilitas adalah penyediaan perlengkapan-perlengkapan fisik untuk member kemudahan kepada konsumen untuk melaksanakan aktifitas-aktifitas sehingga kebutuhan konsumen dapat terpenuhi. Indikator Fasilitas yang digunakan dalam penelitian ini adalah perencanaan spasial, perencanaan ruangan dan perlengkapan atau perabotan.

\section{c. Minat beli ulang}

Menurut Kotler, Philip R., Bowen, John T \& Makens, James. (2014). minat beli timbul setelah adanya proses evaluasi alternati. Dalam proses evaluasi, seseorang akan membuat suatu rangkaian pilihan mengenai produk yang hendak di beli. Indikator minat beli ulang yang digunakan dalam penelitian ini adalah Minat refrensial, minat Exspolatif, dan minat Transaksional.

\section{METODE PENELITIAN}

Penelitian ini dilakukan pada Café Ilo Peta Kota Bima dengan jenis penelitian adalah asosiatif. Populasi dalam penelitian ini adalah pengunjung Café Ilo Peta Kota Bima, sehingga tidak dikatahui dan data secara pasti angka pengunjung, sehingga pengambilan sampel menggunakan rumus Cochra (dalam Riduan, 2015), dimana rumus tersebut digunakan apabila populasi tidak dikatahui, sehingga jumlah sampel yang di gunakan dalam penelitian ini adalah sebesar 96 responden dengan tehnik pengabilan sampel secara isidental, yaitu pengunjung yang dijumpai pada saat pembagian kusioner tersebut.

Sebelum kuisioner dibagikan, terlebih dahulu kuisioner diuji validitas dan reliabiltas menggunakan Aplikasi SPSS Versi 20. Dengan standar pembanding, dikatakan valid 
jika nilai uji validitas $>0.30$ dan dikatakan reliabilitas jika nilai > 0.06 (Sugiyono, 2016). Jumlah dalam kuisioner tersebut sebanyak 28 pernyataan yang terdiri 8 untuk variable Variasi Produk, 12 pernyataan untuk variable Fasilitas dan 8 pernyataam variable minat beli ulang.

Data yang dikumpulkan melalui kuisioner selanjutnya dilakukan analisis menggunakan aplikasi SPSS Versi 16. Adapun uji styatistik yang dilakukan adalah;

a. Uji Asumsi Klasik

Sebelum melakukan analisis regresi, maka perlu dilakukan uji asumsi klasik yang terdiri dari uji normalitas, Multikolinearitas dan Heteroskedastisitas. Hal itu dilakukan, agar data sampel yang diolah mewakili populasi secara utuh. (Ghozali, 2006). Uji Normalitas dimaksudkan untuk melihat apakah data yang diperoleh terdistribusi normal atau tidak. Hal itu dapat dilakukan dengan dua cara yaitu dengan menggunakan grafik histogram dan grafik normal probability plot.

Uji Multikolinearitas merupakan cara untuk mengetahui ada hubungan atau korelasi diantara variabel independen, dalam hal ini variasi produk dan fasilitas. Dikatakan model regresi yang baik jika antar variable independent tidak terdapat hubungan. (Ghozali, 2006) memberi catatan bahwa, dikatakan model regresi yang baik jika besaran VIF (Variance Inflation Factor $)<10$ dan tolerance. Dengan nilai nilai tolerance $>0,10$. Sementara untuk

Uji Heteroskedastisitas adalah untuk mengetahui apakah dalam suatu model regresi terdapat persamaan atau perbedaan varians dari residual satu pengamatan ke pengamatan yang lain, dikatakan model regresi yang baik apabila bersifat homokedastisitas yaitu suatu varians dari residual satu pengamatan ke pengamatan lain tetap, dan sebaliknya disebut heteroskedastisitas. homokedastisitas dapat dilihat dari grafik scatterplot dengan ketentuan Jika terdapat pola tertentu maka mengindikasikan telah terjadi heteroskesdastisitas. Tetapi jika tidak ada pola yang jelas serta titik-titik menyebar di atas dan di bawah angka 0 pada sumbu Y, maka tidak terjadi heteroskedastisitas

b. Uji Statistik

Pada uji statistic menggunakan SPSS Versi 20 ini, ada empat hal yang diperhatikan yaitu persamaan regresi, Koofisien Koerelasi, Koofisien Determinasi, Hubungan Secamara parsila yaitu dilihat dari nilai $t_{\text {hitung }}$ dan hubungan secara simultan dilihat dari nilai $\mathrm{F}_{\text {hitung. }}$

Untuk melihat persamaan regresi, menggunakan persamaan umum linier yaitu $\mathrm{Y}=\mathrm{a}+\mathrm{bX}_{1}+\mathrm{cX}$. Sementara untuk melihat koofisien korelasi dan determinasi diambil Tabel Model Summary ${ }^{b}$ yaitu pada nilai nilai $R$ dan $R$ Square. Sementara untuk nilai hubungan parsial dilihat dari perolehan nilai $t_{\text {hitung dengan }}$ membadingkan dengan nilai table atau dilihat dari perbandingan nilai signifikasinya yaitu nilai sig $<\alpha=0,05$ karena taraf toleransi sebesar $5 \%$. Begitupun dengan uji hubungan secara simultan diperoleh dari perbandingan nilai $F_{\text {hitung dengan membadingkan dengan nilai }}$ $F_{\text {table }}$ dengan ketentuan dikatakan terdapat pengaruh jika $F_{\text {hitung }}>F_{\text {table }}$ atau dilihat dari perbandingan nilai signifikasinya yaitu nilai $\operatorname{si}<\alpha=0,05$ (Santoso, 2000).

\section{HASIL DAN PEMBAHASAN}

a. Uji Validitas dan Rebialitas

Hasil Uji validitas dan reliabilitas akan ditunjukkan oleh table 1. Yang merupakan olahan dari hasil analisis menggunakan aplikasi SPSS Versi 16.

Tabel 1. Hasil Uji Validitas Variabel

\begin{tabular}{|l|l|l|l|l|l|l|}
\hline Variabel & $\begin{array}{l}\text { Rata-rata } \\
\text { hitumg }\end{array}$ & lhimng & Ket & $\begin{array}{l}\text { Cronbach's } \\
\text { alpha }\end{array}$ & $\begin{array}{l}\text { Batas } \\
\text { Normal }\end{array}$ & Ket \\
\hline Variasi Produk & 0,61 & 0,30 & Valid & 0,779 & 0,6 & Rel \\
\hline Vasilitas & 0,52 & 0,30 & Valid & 0,804 & 0,6 & Rel \\
\hline Minat Beli Ulang & 0,53 & 0,30 & Valid & 0,739 & 0,6 & Rel \\
\hline
\end{tabular}

Dari rekapan Tabel 1 diatas, diperoleh nilai rata-rata validitas untuk variasi produk adalah sebesar 0,61, artinya lebih besar dari nilai 0,30 yang distandarkan Sugiyono (2016) artinya pernyataan untuk variasi produk 
dinyatakan valid. Hal yang sama juga untuk pernyataan vasilitas diperoleh nilai validititas lebih dari standar yaitu $0,52>0,30$. Begitupun dengan nilai minat beli produk dilihat dari table tersebut valid. Dilihat dari table 2 diatas, bahwa instrument yang disusun mewakili tiga variable yang ditelilit lebih dari standar reliabilitas yaitu 0,6. Artinya semua instrument yang disusung sangat bagus untuk digunakan. Dilihat dari uji validitas dan uji reliabilitas diatas, maka instrument yang disusun dengan pernyataan yang mewakili masing-masing variable yang di teliti dapat digunakan unruk mengambil data.

\section{d. Uji Asumsi Klasik}

Sebagaimana disinggung diatas, untuk melihat uji normalitas maka menggunakan grafik normal probability plot seperti pada Gambar 1.

Gambar 1. grafik normal probability plot

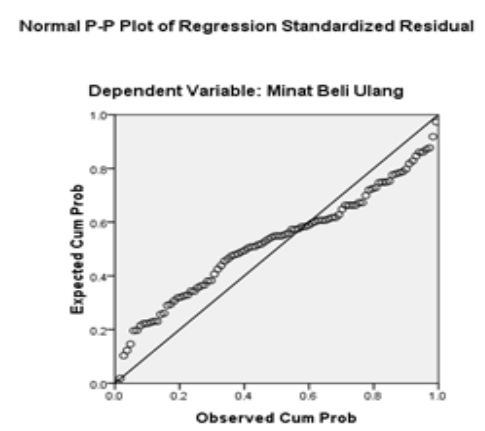

Berdasarkan Gambar 1 di atas, terlihat dengan jelas bahwa selalu mengikuti dan mendekati garis linier yang merupakan garis diagonalnya. Artinya karena mengikuti garis diagonal maka diasumsikan bahwa nilai residual tersebut terdistribusi normal.

$$
\text { Selanjutnya adalah Uji }
$$

Multikolinearitas, Berdasarkan hasil Tabel 5 berikut ini dapat diketahui bahwa setiap variabel memiliki nilai Tolerance tidak kurang dari 0.10 dan nilai Variance Inflation Faktor (VIF) tidak lebih dari 10. Analisis ini menunjukkan bahwa tidak terdapat gejala multikolinearitas terhadap variabel penelitian. Sehingga layak untuk digunakan dalam pengujian selanjutnya.

Tabel 3.

Tabel Uji Multikolinearitas a. Dependent Variable: Minat beli ulang

Untuk uji Uji Heteroskedastisitas, dapat dilihat dari grafik yang ditunjukkan berdasarkan pada Gambar 2 berikut ini;

\section{Gambar 2. Grafik Uji Heteroskedastisitas}

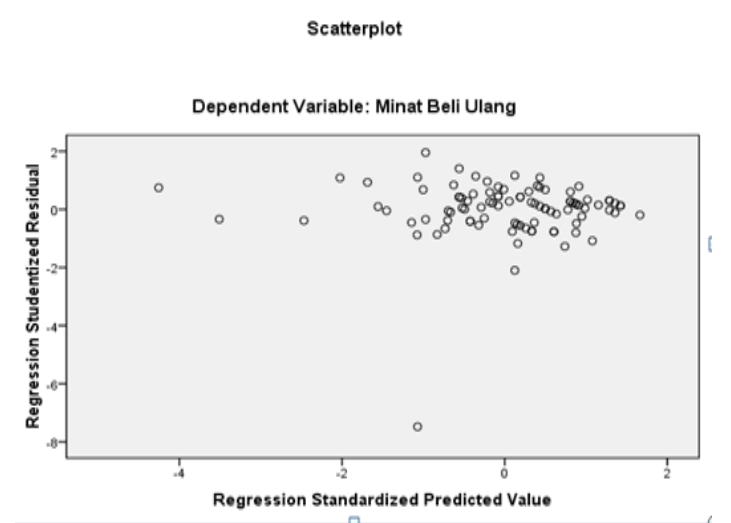

Dari gambar scatterplots diatas dapat dilihat bahwa titik menyebar diatas dan dibawah atau disekitar angka 0. Selain itu juga titik tida mengumpul hanya diatas atau dibawah saja, serta penyebaran titik tidak membentuk pola tertentu. Sehingga dapat disimpulkan bahwa tidak terjadi gejala heterokeastisitas dalam penelitian ini.

1. Uji Statistik

2. Persamaan Regresi

Adapun untuk persamaan Regres dapat dilihat pada taben 3 berikut ini.

\begin{tabular}{|l|l|l|}
\hline \multirow{2}{*}{ Model } & \multicolumn{1}{c|}{ Collinearity Statistik } \\
\cline { 2 - 3 } & Tolerance & VIF \\
\hline (Constant) &, 694 & 1,441 \\
\hline VARIASI PRODUK & & 1,441 \\
\hline FASILITAS &, 694 & \\
\hline
\end{tabular}

Tabel. 4.

Hasil Analisis SPSS Versi 20. Coefficients $^{\mathrm{a}}$

\begin{tabular}{|c|c|c|c|c|c|c|}
\hline \multirow[t]{2}{*}{ Mod } & & \multicolumn{2}{|c|}{$\begin{array}{l}\text { Unstandardized } \\
\text { Coefficients }\end{array}$} & \multirow{2}{*}{$\begin{array}{l}\text { Standardized } \\
\text { Coefficients } \\
\text { Beta }\end{array}$} & \multirow[t]{2}{*}{$t$} & \multirow[t]{2}{*}{ Sig. } \\
\hline & & B & Std. Error & & & \\
\hline \multirow[t]{3}{*}{1} & (Constant) & .013 & 2.518 & & .005 & .996 \\
\hline & Variasi Produk & .959 & .112 & .649 & 8.596 & .000 \\
\hline & Fasilitas & .270 & .091 & .224 & 2.962 & .004 \\
\hline
\end{tabular}

Dari hasil analisis regresi dapat diketahui persamaan regresi berganda adalah $\mathrm{Y}=0,013+0,959 \mathrm{X} 1+0,270 \mathrm{X} 2$. Persamaan tersebut menunjukkan Nilai konstanta sebesar 0,013 dapat di artikan apabila variabel Variasi Produk dan Fasilitas di anggap nol, maka 
Minat Beli Ulang sebasar 0,013. Nilai koefisien bera pada pada variabel Variasi Produk sebesar 0,959 artinya setiap perubahan variabel Variasi Produk (X1) sebesar satu satuan maka akan mengakibatkan perubahan kinerja karyawan sebeasar 0,959 satuan, dengan asumsi-asumsi yang lain adalah tetap. Peningkatan satu satuan pada variabel Variasi Produk akan meningkatkan Minat Beli Ulang sebesar 0,959 satuan. Nilai koefisien beta pada variabel Fasilitas sebesar 0,270 artinya setiap perubahan variabel Fasilitas (X2) sebesar satu satuan, maka akan mengakibatkan perubahan Minat Beli Ulang sebesar 0,270 satuan, dengan asumsi-asumsi yang lain adalah tetap. Peningkatan satu satuan pada variabel Fasilitas akan mengurangi Minat Beli Ulang sebesar 0,270 satuan.

3. Uji Koefisien Korelasi dan Determinasi Tabel 9. Hasil Uji Korelasi dan Determinasi

\begin{tabular}{|l|l|l|l|l|}
\hline Model & R & R Square & $\begin{array}{l}\text { Adjusted } \\
\text { R Square }\end{array}$ & $\begin{array}{l}\text { Std. Error of } \\
\text { the Estimate }\end{array}$ \\
\hline 1 & $.795^{3}$ & .632 & .624 & 3.081 \\
\hline
\end{tabular}

Hasil uji Adjusted $\mathrm{R}^{2}$ pada penelitian ini

diperoleh nilai sebesar 0,795 Hal ini menunjukkan bahwa Minat Beli Ulang $(\mathrm{Y})$ di pengaruhi oleh Variasi Produk) dan Fasilitas $63,2 \%$, sedangkan sisanya sebesar $62,4 \%$ di pengaruhi oleh faktor lain yang tidak termasuk dalam penelitian ini.

4. Hasil Uji t (secara parsial)

Dilihat dari hasil yang ditampilkan oleh tabel 3 diatas, untuk variasi produk diketahui nilai $\mathrm{t}_{\text {hitung }}=8,596>\mathrm{t}$ tabel adalah 1,984 aatau dilihat dari nilai Sig $=0.000<$ 0.05, hal ini berate bahwa Variasi Produk memberi pengaruh terhadap Minat Beli Ulang pada Café Ilo Peta Kota Bima. Hal yang sama juga untuk fasilitas, bahwa dilihat dari nilai xznilai $\mathrm{t}_{\text {hitung }}=2.962>\mathrm{t}$ tabel adalah 1,984 aatau dilihat dari nilai Sig $=0.04<0.05$, hal ini berate bahwa Fasilitas memberi pengaruh terhadap Minat Beli Ulang pada Café Ilo Peta Kota Bima

5. Hasil Uji F (secara Simultan)

Adapun hubungan secara simultan atau hubungan secara bersama-sama variable Variasi Produk dan Fasilitas terhadap minat beli ulang konsumen ditunjukkan pada tabel 5 berikut ini.

Tabel 5.

Data Hubungan secara simultan Variasi Produk dan Fasilitas terhadap minat beli ulang konsumen di Café Ilo Peta.

ANOVA ${ }^{b}$

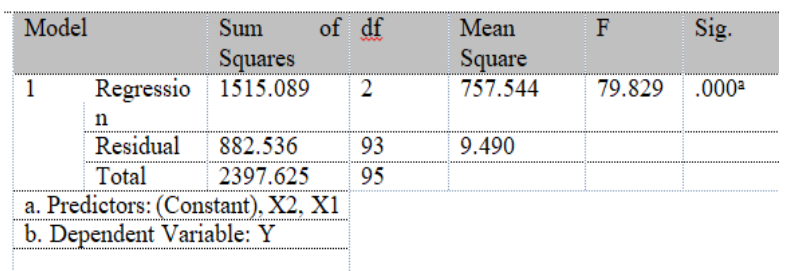

Dari hasil tabe di atas, diperoleh nilai Sig yaitu lebih kecil dari $\alpha$ atau standar error $(0,000<0,05)$, artinya bahwa Variasi Produk dan Fasilitas secara bersama-sama mempengaruhi minat beli ulang pada Café Ilo Peta Kota Bima.

\section{Kesimpulan}

Dari hasil penelitian yang dilakukan, bawah dapat disimpulkan;

a. bahwa Variasi Produk memberi pengaruh terhadap Minat Beli Ulang pada Café Ilo Peta Kota Bima.

b. Hal yang sama juga untuk fasilitas, bahwa Fasilitas memberi pengaruh terhadap Minat Beli Ulang pada Café Ilo Peta Kota Bima dan

c. secara simultan juga bahwa Variasi Produk dan Fasilitas secara bersama-sama mempengaruhi minat beli ulang pada Café Ilo Peta Kota Bima.

\section{Saran}

Ada beberapa saran yang sekiranya dapat dilakukan diantaranya adalah;

a. Peneliti selanjutnya dapat mengambangkan lagi penelitian dengan menambah atau melihat variable lain.

b. Mungkin penelitian tidak hanya menggunakan aplikasi statistic saja, namun juga kedepannya bisa dilakukan manual.

\section{DAFTAR PUSTAKA}

Faradisa. I., Leonardo, B. H., dan Maria Minarsih .2016. Analisi pengaruh variasi produk, fasilitas, dan kualitas pelayanan terhadap minat beli ulang konsumen. Disampaikan pada indonesia coffeeshop semarang (icos 
cafe). Jurnal of management volumen 2 No.

Kotler, Philip Dan Kevin Lane Keller. 2009. Manajemen Pemasaran. Edisi 13 Jilid satu. Erlangga : Jakarta

Kotler, Philip R., Bowen, John T \& Makens, James. (2014). Marketing for Hospitality and Tourism: Sixth Edition. Pearson Education Limited. London.

Riduwan. (2015). Dasar-Dasar Statistika, Bandung: Alfabeta.

sulastyono, A. 1999. Manajemen Penyelenggaraan Hotel. Bandung; Alfabeta

Sugiyono. (2016). Metode Penelitian Kuantitatif Kualitataif dan Kombinasi (Mixed Methods). Bandung: Alfabeta

Ghozali, Imam. 2006. Analisis Multivariate dengan Program SPSS. Edisi Ke 4. Badan Penerbit Universitas Diponegoro. Semarang 